\title{
Futbol Antrenörlerinin Girişimcilik Eğilimleri ve Teknolojik Yeteneklerinin İncelenmesi ${ }^{*}$
}

\author{
Yeliz ERATLI ŞIRIN ${ }^{3 \dagger}$ BD Berna CAN ${ }^{2}$ iD İbrahim ŞEKER ${ }^{2}$ iD Tayfun
${ }^{1}$ Kaahramanmaraş Sütçü İmam Üniversitesi, Spor Bilimleri Fakültesi, KAHRAMANMARAŞ
${ }^{2}$ Çukurova Üniversitesi, Sağlı Bilimleri Enstitüsü, ADANA \\ ${ }^{3}$ Çukurova Üniversitesi, Spor Bilimleri Fakültesi, ADANA
}

d DO DOI: $10.31680 /$ gaunjss.976372

Orijinal Makale / OriginalArticle

Geliş Tarihi / Received:31.07.2021

Kabul Tarihi / Accepted:01.09.2021

Yayın Tarihi / Published: 20.09.2021

Öz

$\mathrm{Bu}$ araştırma futbol antrenörlerinin girişimcilik eğilimleri ve teknolojik yeteneklerinin incelenmesi amacıyla yapılmıştır. Bu çalışma nicel araştırma modeline göre tasarlamış olup, ilişkisel tarama modeli çerçevesinde yürütülmüştür. Araştırmanın evrenini Akdeniz bölgesi, örneklemini ise Adana, ilinden seçkisiz olmayan örnekleme yöntemlerinden uygun (kazara) örnekleme yöntemiyle seçilmiş 8'i kadın 109'u erkek olmak üzere toplam 117 futbol antrenörü oluşturmaktadır. Araştırmada veri toplama aracı olarak anket kullanılmıştır. Araştırmada kullanılacak olan anket formları araştırmacı tarafından online anket yöntemiyle katıımcılara ulaştııımıştır. Araştırmada katılımcıların demografik özelliklerini elde etmek için "Kişisel Bilgi Formu" kullanılmıştır. Ayrıca katılımcıların girişimcilik yönelimlerini ölçmek için Deveci ve Çepni (2015) tarafından geliştirilen "Girişimcilik Ölçeği", katılımcıların teknolojik yeteneklerini ölçmek için ise, Eren ve Çiçeklioğlu (2020) tarafından Türkçeye uyarlanan "Teknolojik Yetenekler Ölçeği” kullanılmıştır. Araştırmada elde edilen veriler SPSS programı aracılı̆̆ıla bilgisayar ortamında analiz edilmiştir. Elde edilen bulgular değerlendirildiğinde, eğitim durumu, antrenörlükte çalışma yılı ve aylık gelir durumu ve teknoloji kullanımı ile ilgili ders/kurs alma değişkenlerinin antrenörlerin girişimcilik eğilimleri ve teknolojik yetenekleri üzerinde kısmen de olsa etkili olduğu söylenebilir. Bununla birlikte yaş değiş̧kenin de antrenörlerin girişimcilik eğilimleri üzerinde etkili olduğu görülmektedir. Ayrıca, girişimcilik ölçeğinin alt boyutları ve teknolojik yetenekler arasında da orta düzeyde pozitif yönlü ilişki olduğu görülmektedir.

Anahtar Kelimeler: Antrenör, Girişimcilik, Teknolojik Yetenekler

\section{Investigation of EntrepreneurshipTendencies and Technological Skills of Football Trainers}

\begin{abstract}
This research was conducted to examine the entrepreneurial tendencies and technological capabilities of football coaches. This study was designed according to the quantitative research model and was carried out within the framework of the relational survey model. The universe of the research consists of the Mediterranean region, and the sample consists of 117 football coaches, 8 women and 109 men, who were selected by convenient (accidental) sampling method from non-random sampling methods from Adana. Questionnaire was used as a data collection tool in the research. Questionnaire forms to be used in the research were delivered to the participants by the researcher using the online questionnaire method. In theresearch, "Personal Information Form" was used to obtain the demographic characteristics of the participants. In addition, the "Entrepreneurship Scale" developed by Deveci and Cepni (2015) was used to measure the entrepreneurial orientation of the participants, and the "Technological Capabilities Scale" adapted into Turkish by Eren and Çiçekoğlu (2020) to measure the technologic capabilities of the participants. The data obtained in the research were analyzed in the computer environment throught he SPSS program. When the findings are evaluated, the variables of education level, working years and monthly income in coaching, taking courses courses related to technology use are partially effective on the entrepreneurial tendencies and technological abilities of the coaches. However the age variable is also effective on the entrepreneurial tendencies of the coaches. In addition, there is a moderate positive relationship between the sub-dimensions of the entrepreneurship scale and technologic alabilities. Keywords: Football, Coach, Entrepreneurship, TechnologicalTalents
\end{abstract}

* Bu çalışma "Çok Disiplinli Bakış Açısıyla Sporda Eşitlik ve Çeşitlilik Üzerine Uluslararası Konferans, Avrupa Birliği, Erasmus + Programı desteğiyle GESPORT, Online Kongre, 2021'de özet bildiri olarak sunulmuştur. 


\section{Giriş}

Girişimcilik kavramı, risk almaya eğilimli olma ve uygulamaya geçme olarak ve aynı zamanda olağan durumda ortaya çıkan fırsat ve imkanları değerlendirme ve fırsat yaratma olarak da tanımlanmaktadır. Piyasadaki eksiklikleri tespit ederek diğer kişilerden daha fazla öngörülü olarak hareket eden kişi ise "Girişimci" olarak tanımlanmaktadır (Işık ve ark., 2011). Girişimcilik bölgedeki işsizlik sorununa karşı önemli bir çözüm yolu yaratırken aynı zamanda ekonomik büyümeye katkı sağlamaktadır. Girişimcinin en önemli faydalarından biri ekonomik kaynakların düşük üretkenlik alanlarından yüksek alanlara aktarılma sürecidir. Bunun nedeni olarak üretim kaynaklarını farklı bir model ve düşünce tarzı ile birleştirerek kullanılmayan her bir üretim faktörlerinin yararlı hale getirilerek kullanılmasını sağlamaktır. Kişilere iş imkanı sağlaması, ekonomik ve toplumsal yapıya değişimci/inovasyoncu bir anlayış kazandırıması, Girişimciliğin kalkınma açısından faydaları sayılmaktadır. Bu faydaların sağlanabilmesi ve uygulanabilmesi bireyin içinde bulunduğu sosyoekonomik ve kültürel yapı, aile, toplumsal davranış örüntüleri, eğitimin kalitesi, genel ekonomik koşullar ile devletin girişimciliğin gelişmesine ilişkin teşvik edici tutum ve politikaları önem kazanmaktadır. Bu sayede girişimcilik özelliklerine sahip olan kişiler atılımda bulunacak ve ulusal kaynaklı büyüme sağlanabilecektir (Çetinkaya Bozkurt ve ark., 2012). Özellikle bu açıdan bakıldığında dünyada çok büyük bir sektör olarak bilinen spor sektöründe de yerel girişimciliğin önemi artmaktadır. Bununla beraber, bir bilim alanı olarak spor, psikoloji, sosyoloji, felsefe, yönetim, pazarlama gibi birçok disiplin tarafından çalışıldığı halde kendisini başı başına bir disiplin olarak henüz tanımlayan spor girişimciliğine odaklanılmış çalışmalarda önemli eksiklikler bulunmaktadır. Hâlbuki spor pazarlamacıları, girişimciliğe odaklanarak organizasyonlarını ve müşterilerini daha değerli hale getirebilirler. Ayrıca spor örgütlerinin büyümesinde spor girişimciliğinin önemi kendini daha fazla göstermektedir (Ratten, 2011).

Özellikle günümüzde hayatımızı düzenli olarak devamlılığını sağlamak için kullandığımız bir araç olan teknoloji, zamana ve mekâna göre değişim göstermektedir. MacKenzie ve Wajcman (1993) teknolojiyi, fiziki objeler, insan eylemleri ile bunları birleştirip bağlayan bilgiler olarak tanımlamıştır. Özetle teknoloji, insani olan ve olmayan unsurların ayrıştırımasıdır. "İnsani olmayan" daha çok maddesel ve teknik olarak, "insani olan" sosyal unsurlarla ilişkili olarak değerlendirilmektedir (Grint ve Woolgar, 1997). Teknolojik yetenekler ise, teknolojiyi, 
Eratlı Şirin, Y., Can B., Şeker, İ, ve Şirin, T. (2021). Futbol Antrenörlerinin Girişimcilik Eğilimleri ve Teknolojik Yeteneklerinin İncelenmesi. Gaziantep Üniversitesi Spor Bilimleri Dergisi, 6(3), 279 - 297.

ana rekabet unsuru olarak ekonomik değere çevirebilme, geliştirebilme becerilerinin bütünüdür (Akyos, 2006).

Spor, sağlık, eğitim, ekonomi vb. alanlarda teknolojinin gelişmesi ve yaygınlaşması ile teknolojiyi kullanan sayısındaki artış bir zorunluluk haline gelmiştir $\mathrm{Bu}$ sayede dünyanın her yerindeki bilgiye kolay ulaşım, birçok veri ve kaynağı birleştirebilme ve çözümleyebilme imkanı sayesinde yeni güncel bilgiler üretilmesine olanak tanımıştır. Ekonomik ve sosyal değişimin önemli bir unsuru haline gelen teknolojinin sporda ve sporun her alanında kullanımı hızla artmış ve vazgeçilmez bir hale gelmiştir (İçli, 2001).

Örneğin futbolda, hakemlere karar vermede yardımcı olmak ve bir maç sırasında sporcuların performansını ölçmek, antrenmanlarda sporcuların motorik özelliklerini belirlemek, maç veya müsabaka sırasında sonuçların daha adil bir şekilde belirlenmesini sağlamak gibi farklı nedenlerle yeni cihazlar kullanmak antrenörün antrenman programını ve oyun stratejisini belirlemesine yardımcı olmak gibi birçok alana katkı sağlamaktadır.

Futbolda tanıtılan en ünlü ve en yeni teknolojilerden biri "gol çizgisi teknolojisi" olarak adlandırılır. Hakemi desteklemek için bir topun kale çizgisini geçip geçmediğini belirlemek için kullanılır. Bunun yerine, bir futbol maçı sırasında sporcuların performansının ölçülmesine gelince, son birkaç yılda farklı türden cihazlar üretildi. Kalp atış hızını izleyebilen giyilebilir cihazlar, sporcuların hareketlerini ve fiziksel taleplerini tanımlamak için kullanılan küresel konumlandırma sistemi (GPS), ivme ölçer ve jiroskop sensörlerini içeren izleme teknolojileriyle entegre edildi. Bu nedenle, bu yeni teknolojiler bir maç sırasında meydana gelen çarpışma ve sıçrama sayısını değerlendirebilir. Bu veriler antrenörler ve doktorlar için giderek daha önemli hale geldi. Aslında antrenörler, takımlarına daha iyi stratejiler sağlamak için bunları kullanır. Oyuncularının sahada tam olarak nerede ve nasıl hareket ettiğini bilerek, her pozisyon için en iyi oyuncuyu seçebilir veya rakiplerinin seviyesine göre bir oyuncuyu değiştirebilirler. Antrenörler bu verileri, sezon öncesi ve normal sezon boyunca antrenman seanslarını planlamak için kullanır ve her sporcu için özelleştirilmiş ölçülebilir antrenman rutinleri sağlamak için teknolojileri kullanır. Örneğin, bazı teknolojiler oyunun hem fizyolojik hem de psikolojik unsurlarını geliştirmek için tasarlanmıştır. Dahası, atletik antrenörler, takım doktorları ve antrenörler, oyuncular fiziksel eşiklerini aşmak üzereyken yaralanmaları önlemek için kalp atış hızı ve sensör verilerini kullanabilir. Son zamanlarda, büyük kulüpler, potansiyel olarak ilginç oyuncuları keşfetmek için bu yeni teknolojiler tarafından sağlanan verileri kullandı. 
Eratlı Şirin, Y., Can B., Şeker, İ, ve Şirin, T. (2021). Futbol Antrenörlerinin Girişimcilik Eğilimleri ve Teknolojik Yeteneklerinin İncelenmesi. Gaziantep Üniversitesi Spor Bilimleri Dergisi, 6(3), 279 - 297.

Sonuç olarak, yeni teknolojilerin kullanımının sadece futbolcu yetiştirme ve futbol oynama şeklini değil, aynı zamanda dünyanın en popüler sporunu yaşama ve izleme deneyimini de değiştirdiği söylenebilir (https://www.technogym.com).

Spor endüstrinin büyümesi, sporun çeşitli alanları ile ilgili işler kurmak ve işletmek için girişimcilik eğilimi olan insanlara çeşitli fırsatlar ortaya çıkmaya başladı. Görevi sadece beceri ve taktik talimat vermekten, spor organizasyonlarının başarısı için kritik olan birden fazla işlevi yerine getirmeleri gereken bir işe dönüşen spor antrenörleri son zamanlarda antrenörlerin yüksek ciroları nedeniyle çok sayıda zorlukla karşı karşıya kalmaktadırlar. Çoğu durumda, spor antrenörlerinin kısa vadeli sözleşmeler ve iş istikrarsızlığı ile belirsiz geleceklerle karşı karşıya kalmaktadırlar. (Surujlal, 2004). Bunun nedeni ise bireysel veya takım sporlarında elde edilen başarısızlık nedeni, sporculardan veya yönetimden önce sorumlu olarak antrenörler görülmektedir. Bu nedenle birçok spor antrenörünün iş sürekliliğinin garanti edilmemesinin bir sonucu olarak, antrenörlükte profesyonel ve girişimci olarak kendine güvenen kariyerler çoğalmaktadır. Spor antrenörlerinin, yaşam boyu istihdam için spor organizasyonlarına bağımlı olmak yerine, kariyerlerine farklı bir açıdan-girişimcilik açısından yaklaşmak zorunda kalmaktadırlar.

Bundan sonraki dönemde sadece spor girişimciliğinde değil her alanda bireylerin teknoloji kullanma yeteneklerinin geliştirilmesi ve bu kazanımları uygulanması gerekmektedir. Spor antrenörlerinin, girişimci eğilimi ve teknolojik yetenekleri ile ilgili yapılan literatür araştırması, özellikle konuya odaklanan çok az çalışmanın olduğunu ortaya çıkartmıştır. Dolayısıyla bu çalışmanın amacı spor antrenörlerinin girişimci eğilimlerinin teknolojik yeteneklerine etkisini araştırmaktır.

\section{Yöntem}

\section{Araştırma Modeli}

Araştırmanın bu bölümünde modeline, evren ve örneklemine, veri toplama araçlarına, verilerin toplanmasına ve çözümlenmesine ilişkin bilgilere yer verilmiştir. Araştırma için 9 Temmuz 2021 tarihinde etik kurul onayı (Toplantı sayısı 113 karar no: 26) alınmıştır.

\section{Evren ve Örneklem}

Araştırma grubunun evrenini; Akdeniz bölgesinde bulunan futbol antrenörleri oluşturmaktadır. Araştırmanın örneklemini ise; Adana ilinden 8'i kadın 109'u erkek olmak üzere toplam 117 futbol antrenörü oluşturmaktadır. 


\section{Veri Toplama Aracı}

$\mathrm{Bu}$ araştırmada veri toplama aracı olarak anket yöntemi kullanılmıştır. Dört bölümden oluşan anketin birinci bölümünde "Kişisel Bilgi Formu", ikinci bölümünde, “Öğretmen Adaylarına Yönelik Girişimcilik Ölçeği”, üçüncü bölümde ise, "Teknolojik Yetenekler Ölçeği” kullanılmıştır.

Girişimcilik Ölçeği: Deveci ve Çepni (2015) tarafından öğretmen adaylarının girişimcilik yönelimlerini ölçmeyi amaçlayan "Öğretmen Adaylarına Yönelik Girişimcilik Ölçeği" 5 boyutlu, 38 maddeli ve 5'li likert tipindedir. Bu ölçek daha önce Şirin (2019) tarafından "Antrenörlerin girişimcilik Eğilimlerinin Belirlenmesi” adlı çalışmada bu ölçek spor antrenörlerine uygulanmış ve güvenirlilik açısından antrenörlerin girişimcilik özelliklerini belirlemeye yönelik uygun olduğu görülmüştür. Antrenörler sporcular için eğitimci konumunda olduğundan doyalı bu çalışma için bu ölçeğin kullanılması uygun görülmüştür. Girişimcilik ölçeğinin boyutları; "Risk Alma (14 madde)", "Fırsatları Görme (12 madde)", "Kendine Güven (14 madde)", "Duygusal Zekâ (12 madde)"ve "Yenilikçi Olma (11 madde)" olarak tanımlanmıştır. Ölçekten alınabilecek en düşük puan “38” en yüksek puan “190” dır. Bu araştırmada ise Cronbach Alpha değeri ise 899 olarak bulunmuştur.

Teknolojik Yetenekler Ölçeği: Zhou ve Wu (2010) tarafından işletmelerin teknolojik yetenekleri, stratejik esneklikleri ve ürün inovasyonunu ölçmek amacıyla geliştirilmiş, Eren ve Çiçeklioğlu (2020) tarafından Türkçeye uyarlanmıştır. Bu çalışmada antrenörlerin teknolojik yeteneklerini ölçmek amacıyla "Teknolojik Yetenekler" alt boyutu revize edilerek araştırmaya dâhil edilmiştir. Teknolojik yetenekler alt boyutu 5 maddeli ve 5'li likert tipindedir. Bu alt boyuttan alınabilecek en düşük puan "5" en yüksek puan "25" dir. Bu araştırmada ise Cronbach Alpha değeri ise .878 olarak bulunmuştur.

\section{Verilerin Analizi}

Araştırma verileri SPSS 21 paket programı ile analiz edilmiştir. Tanımlayıcı istatistiklerin yanı sıra; dağılımların normallik yapısı Kolmogorov-Smirnov'a göre: (Risk Alma: ,000; Fırsatları Görme: ,000; Kendine Güven: ,000; Duygusal Zeka: ,000; Yenilikçi Olma: ,041; Teknolojik Yetenek: ,001) şeklinde bulunmuştur. Veriler normal dağılım göstermediği için non-parametrik test kararı alınmıştır. İkili değişkenlere ilişkin farkları belirlemek amacıyla bağımsız Mann-Whitney $U$ testi, ikiden fazla gruplar arasındaki farkları belirlemek amacıyla Kruskal-Wallis $\mathrm{H}$ analizi, ilişki karşılaştırmalarında ise spearman correlation analizi kullanılış̧ır. 


\section{Bulgular}

Tablo 1. Tanımlayıcı İstatistikler - Yüzde ve Frekans Dağılımları

\begin{tabular}{|c|c|c|c|}
\hline & & $f$ & $\%$ \\
\hline \multirow{2}{*}{ Cinsiyet } & Kadın & 8 & 6,8 \\
\hline & Erkek & 109 & 93,2 \\
\hline \multirow{3}{*}{ Eğitim Durumu } & Lise & 20 & 17,1 \\
\hline & Ön Lisans/Lisans & 69 & 59,0 \\
\hline & Lisansüstü & 28 & 23,9 \\
\hline \multirow{4}{*}{ Aylık Gelir Durumu } & $1500-3000 \mathrm{TL}$ & 24 & 20,5 \\
\hline & $3001-4500 \mathrm{TL}$ & 27 & 23,1 \\
\hline & 4501-6000 TL & 34 & 29,1 \\
\hline & 6000 TL ve Üzeri & 32 & 27,4 \\
\hline \multirow{4}{*}{ Antrenörlükte Çalışma Yılı } & $1-3 Y_{\imath I}$ & 31 & 26,5 \\
\hline & $4-7 Y_{I I}$ & 31 & 26,5 \\
\hline & $8-11 \mathrm{YII}$ & 24 & 20,5 \\
\hline & 12 Yıl ve Üzeri & 31 & 26,5 \\
\hline \multirow{5}{*}{ Antrenörlük Belge Kademesi } & UEFA A Lisanslı Antrenör & 18 & 15,4 \\
\hline & UEFA B Lisanslı Antrenör & 33 & 28,2 \\
\hline & TFF Teknik Direktör & 3 & 2,6 \\
\hline & TFF B Lisanslı Antrenör & 5 & 4,3 \\
\hline & TFF Grassroots C Lisanslı Antrenör & 58 & 49,6 \\
\hline \multirow{2}{*}{ Girişimcilik Eğitimi Aldınız Mı? } & Evet & 20 & 17,1 \\
\hline & Hayır & 97 & 82,9 \\
\hline \multirow{2}{*}{ Ailenizde Girişimci Olan Var Mı? } & Evet (Var) & 11 & 9,4 \\
\hline & Hayır (Yok) & 106 & 90,6 \\
\hline \multirow{2}{*}{$\begin{array}{l}\text { Teknoloji Kullanımı İle İlgili Ders veya } \\
\text { Kurs Aldınız Mı? }\end{array}$} & Evet & 65 & 55,6 \\
\hline & Hayır & 52 & $\overline{44,4}$ \\
\hline Toplam & & 117 & 100 \\
\hline
\end{tabular}

Tablo 1 incelendiğinde, katılımcıların; \%6,8'i kadın (n=8), \%93,2'si erkektir (n=109). \%17,1'si lise ( $n=20)$, \%59,0'u önlisans/lisans ( $n=69)$ eğitim almıştır. \%20,5'i 15003000 TL (n=24), \%29,1'ü 4501-6000 TL ve üzeri $(n=34)$ aylık gelire sahiptir. \%20,5’i 8-11 yıl (n=24), \%26,5 1-3, 4-7, 12 yıl ve üzeri çalışma yılına sahiptir. Katılımcıların \%17,11 girişimcilik eğitimi alırken $(n=20)$, \%83,9'u girişimcilik eğitimi almamıştır ( $n=97)$.Katılımcıların \%9,4'ünün ailesinde girişimci varken ( $n=11)$, \%90,6'sının ailesinde girişimci yoktur $(n=106)$. Katılımcıların \%55,6'sı teknoloji ile ilgili ders alırken ( $n=65), \% 44,4$ 'ü teknoloji ile ilgili ders almamıştır $(n=52)$. 
Tablo 2.Tanımlayıcı İstatistikler - Ortalama ve Standart Sapma

\begin{tabular}{cccccc}
\hline & $\overline{\mathbf{X}}$ & $\mathbf{S}$ & Min. & Max. & $\mathbf{n}$ \\
\hline Yaş & 40,40 & 8,37 & 22,00 & 61,00 & 117 \\
\hline
\end{tabular}

Tablo 2 incelendiğinde, katılımcıların yaş ortalaması $(\bar{x}), 40,40$ standart sapması (S), 8,37 en küçük yaş değeri 22, en büyük yaş değeri ise 61 olarak saptanmıştır.

Tablo 3.ÖAYGÖ ve TYÖ Alt Boyutlarına İlişkin Ortalama ve Standart Sapma

\begin{tabular}{|c|c|c|c|c|c|c|}
\hline & Alt Boyutlar & $\overline{\mathbf{X}}$ & $\mathrm{S}$ & Min. & Max. & $\mathbf{n}$ \\
\hline \multirow{5}{*}{ 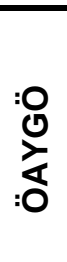 } & Risk Alma & 28,75 & 3,62 & 15,00 & 35,00 & \multirow{6}{*}{117} \\
\hline & Fırsatları Görme & 38,35 & 5,07 & 12,00 & 45,00 & \\
\hline & Kendine Güven & 30,64 & 3,93 & 9,00 & 35,00 & \\
\hline & Duygusal Zekâ & 33,34 & 3,77 & 17,00 & 40,00 & \\
\hline & Yenilikçi Olma & 26,88 & 3,55 & 16,00 & 35,00 & \\
\hline : & Teknolojik Yetenekler & 19,19 & 4,36 & 5,00 & 25,00 & \\
\hline
\end{tabular}

Tablo 3'te ÖAYGÖ alt boyutlarından "Fırsatları görme" $(38,35 \pm 5,07)$ en yüksek, "Yenlikçi olma" alt boyutu $(26,88 \pm 3,55)$ en düşük ortalamaya sahip. Teknolojik yetenekler ölçeğinin ortalaması $(19,19 \pm 4,36)$ olarak saptanmıştır.

Tablo 4. Katılımcıların eğitim durumu değişkenine ilişkin Kruskal-Wallis testi sonuçları

\begin{tabular}{|c|c|c|c|c|c|c|c|c|}
\hline & & Eğitim Durumu & $\mathbf{N}$ & S.o & $x^{2}$ & Sd & p & $\begin{array}{c}\text { Anlamlı } \\
\text { Fark }\end{array}$ \\
\hline \multirow{15}{*}{$\begin{array}{l}: 0 \\
\stackrel{0}{\bigcup} \\
\text { : }\end{array}$} & \multirow{3}{*}{ Risk Alma } & 1.Lise & 20 & 74,10 & \multirow{3}{*}{7,530} & \multirow{3}{*}{2} & \multirow{3}{*}{0,02} & \multirow{3}{*}{$3-1^{*}$} \\
\hline & & 2.Ön Lisans/Lisans & 69 & 59,46 & & & & \\
\hline & & 3.Lisansüstü & 28 & 47,09 & & & & \\
\hline & \multirow{3}{*}{$\begin{array}{l}\text { Fırsatları } \\
\text { Görme }\end{array}$} & 1.Lise & 20 & 63,18 & \multirow{3}{*}{0,987} & \multirow{3}{*}{2} & \multirow{3}{*}{0,61} & \multirow{3}{*}{-} \\
\hline & & 2.Ön Lisans/Lisans & 69 & 56,43 & & & & \\
\hline & & 3.Lisansüstü & 28 & 62,36 & & & & \\
\hline & \multirow{3}{*}{$\begin{array}{l}\text { Kendine } \\
\text { Güven }\end{array}$} & 1.Lise & 20 & 57,95 & \multirow{3}{*}{0,475} & \multirow{3}{*}{2} & \multirow{3}{*}{0,78} & \multirow[b]{3}{*}{-} \\
\hline & & 2.Ön Lisans/Lisans & 69 & 57,75 & & & & \\
\hline & & 3.Lisansüstü & 28 & 62,82 & & & & \\
\hline & \multirow{3}{*}{$\begin{array}{c}\text { Duygusal } \\
\text { Zekâ }\end{array}$} & 1.Lise & 20 & 62,60 & \multirow{3}{*}{0,620} & \multirow{3}{*}{2} & \multirow{3}{*}{0,73} & \multirow{3}{*}{ - } \\
\hline & & 2.Ön Lisans/Lisans & 69 & 56,98 & & & & \\
\hline & & 3.Lisansüstü & 28 & 61,41 & & & & \\
\hline & \multirow{3}{*}{$\begin{array}{l}\text { Yenilikçi } \\
\text { Olma }\end{array}$} & 1.Lise & 20 & 66,75 & \multirow{3}{*}{2,850} & \multirow{3}{*}{2} & \multirow{3}{*}{0,24} & \multirow{3}{*}{ - } \\
\hline & & 2.Ön Lisans/Lisans & 69 & 54,66 & & & & \\
\hline & & 3.Lisansüstü & 28 & 64,16 & & & & \\
\hline \multirow{3}{*}{$: 0$} & \multirow{3}{*}{$\begin{array}{l}\text { Teknolojik } \\
\text { Yetenekler }\end{array}$} & 1.Lise & 20 & 58,40 & \multirow{3}{*}{0,028} & \multirow{3}{*}{2} & \multirow{3}{*}{0,98} & \multirow{3}{*}{ - } \\
\hline & & 2.Ön Lisans/Lisans & 69 & 58,81 & & & & \\
\hline & & 3.Lisansüstü & 28 & 59,89 & & & & \\
\hline
\end{tabular}

Anlamlı farkın lehine olduğu gruplar (*) ile gösterilmiştir. 
Eratlı Şirin, Y., Can B., Şeker, İ, ve Şirin, T. (2021). Futbol Antrenörlerinin Girişimcilik Eğilimleri ve Teknolojik Yeteneklerinin İncelenmesi. Gaziantep Üniversitesi Spor Bilimleri Dergisi, 6(3), 279 - 297.

Tablo 4 incelendiğinde, katılımcıların eğitim durumu değişkenine göre ÖAYGÖ'nin risk alma alt boyutunda istatistiksel olarak anlamlı fark tespit edilmiştir $(p<0,05)$. ÖAYGÖ'nin diğer hiçbir alt boyutları ve TYÖ'nde ise istatistiksel olarak fark görülmemiştir ( $p>0,05)$.

Tablo 5. Katılımcıların aylık gelir değişkenine ilişkin Kruskal-Wallis testi sonuçları

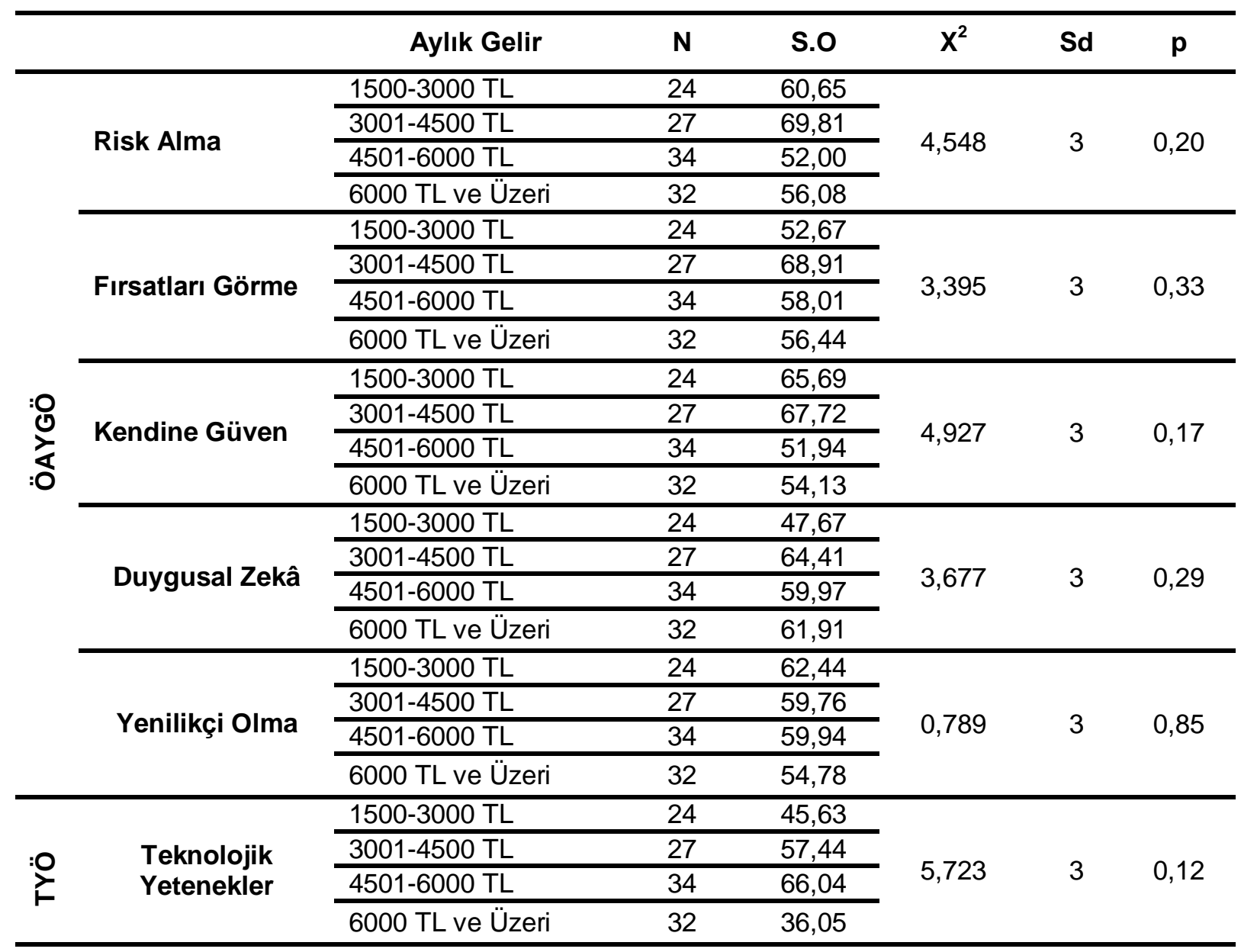

Tablo 5 incelendiğinde, katılımcıların aylık gelir durumlarına göre ÖAYGÖ'nin alt boyutları ve TYÖ'de istatistiksel olarak fark görülmemiştir $(p>0,05)$. 
Eratlı Şirin, Y., Can B., Şeker, İ, ve Şirin, T. (2021). Futbol Antrenörlerinin Girișimcilik Eğilimleri ve Teknolojik Yeteneklerinin İncelenmesi. Gaziantep Üniversitesi Spor Bilimleri Dergisi, 6(3), 279 - 297.

Tablo 6. Katılımcıların antrenörlük çalışma yılı değişkenine ilişkin Kruskal-Wallis testi sonuçları

\begin{tabular}{|c|c|c|c|c|c|c|c|c|}
\hline & & Çalışma Yılı & $\mathbf{N}$ & S.O & $x^{2}$ & Sd & $\bar{p}$ & Anlamlı Fark \\
\hline \multirow{20}{*}{ 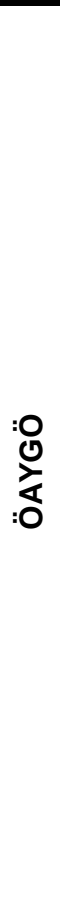 } & \multirow{4}{*}{ Risk Alma } & $1.1-3 Y_{\mathrm{II}}$ & 31 & 58,24 & \multirow{4}{*}{4,150} & \multirow{4}{*}{3} & \multirow{4}{*}{0,24} & \multirow{4}{*}{-} \\
\hline & & 2.4-7 YII & 31 & 67,97 & & & & \\
\hline & & 3.8-11 Yıl & 24 & 59,27 & & & & \\
\hline & & 4.12 YIl ve Üzeri & 31 & 50,58 & & & & \\
\hline & \multirow{4}{*}{$\begin{array}{l}\text { Fırsatları } \\
\text { Görme }\end{array}$} & 1.1-3 Yıl & 31 & 59,73 & \multirow{4}{*}{1,412} & \multirow{4}{*}{3} & \multirow{4}{*}{0,70} & \multirow{4}{*}{-} \\
\hline & & 2.4-7 YII & 31 & 64,03 & & & & \\
\hline & & 3.8-11 YII & 24 & 58,04 & & & & \\
\hline & & 4.12 Yıl ve Üzeri & 31 & 53,98 & & & & \\
\hline & \multirow{4}{*}{$\begin{array}{l}\text { Kendine } \\
\text { Güven }\end{array}$} & $1.1-3 Y_{\text {II }}$ & 31 & 46,45 & \multirow{4}{*}{10,371} & \multirow{4}{*}{3} & \multirow{4}{*}{0,01} & \multirow{4}{*}{$\begin{array}{l}2^{*}-1 \\
2^{*}-4\end{array}$} \\
\hline & & 2.4-7 YII & 31 & 73,79 & & & & \\
\hline & & 3.8-11 Y II & 24 & 57,79 & & & & \\
\hline & & 4.12 Yıl ve Üzeri & 31 & 57,69 & & & & \\
\hline & \multirow{4}{*}{ Duygusal Zekâ } & $1.1-3 Y_{I I}$ & 31 & 49,05 & \multirow{4}{*}{4,873} & \multirow{4}{*}{3} & \multirow{4}{*}{0,18} & \multirow{4}{*}{-} \\
\hline & & 2.4-7 YII & 31 & 67,66 & & & & \\
\hline & & 3.8-11 YII & 24 & 61,31 & & & & \\
\hline & & 4.12 Yıl ve Üzeri & 31 & 58,50 & & & & \\
\hline & \multirow{4}{*}{ Yenilikçi Olma } & $1.1-3 Y_{I I}$ & 31 & 56,71 & \multirow{4}{*}{0,631} & \multirow{4}{*}{3} & \multirow{4}{*}{0,88} & \multirow{4}{*}{-} \\
\hline & & 2.4-7 $Y_{I I}$ & 31 & 62,47 & & & & \\
\hline & & 3.8-11 YII & 24 & 60,27 & & & & \\
\hline & & 4.12 Yıl ve Üzeri & 31 & 56,84 & & & & \\
\hline \multirow{4}{*}{$: 0$} & \multirow{4}{*}{$\begin{array}{l}\text { Teknolojik } \\
\text { Yetenekler }\end{array}$} & 1.1-3 Yıl & 31 & 62,85 & \multirow{4}{*}{7,349} & \multirow{4}{*}{3} & \multirow{4}{*}{0,06} & \multirow{4}{*}{ - } \\
\hline & & 2.4-7 YII & 31 & 46,29 & & & & \\
\hline & & 3.8-11 YII & 24 & 70,00 & & & & \\
\hline & & 4.12 Yıl ve Üzeri & 31 & 59,34 & & & & \\
\hline
\end{tabular}

Anlamlı farkın lehine olduğu gruplar $\left(^{*}\right)$ ile gösterilmiştir.

Tablo 6 incelendiğinde, katılımcıların antrenörlükte çalışma yılı değişkenine göre ÖAYGÖ'nin kendine güven alt boyutunda istatistiksel olarak anlamlı fark tespit edilmiştir $(p<0,05)$.

Tablo 7. Katılımcıların girişimcilik eğitimi alma durumlarına ilişkin Mann-Whitney U testi sonuçları

\begin{tabular}{|c|c|c|c|c|c|c|c|}
\hline & & $\begin{array}{c}\text { Girişimcilik } \\
\text { Eğitimi }\end{array}$ & $\mathbf{N}$ & S.o & S.T & $\mathbf{U}$ & p \\
\hline \multirow{10}{*}{ 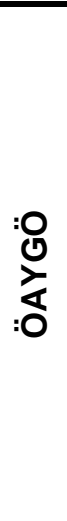 } & \multirow{2}{*}{ Risk Alma } & Evet & 20 & 69,00 & 1380,00 & \multirow{2}{*}{770,00} & \multirow{2}{*}{0,14} \\
\hline & & Hayır & 97 & 56,94 & 5523,00 & & \\
\hline & \multirow{2}{*}{ Fırsatları Görme } & Evet & 20 & 72,48 & 1449,50 & \multirow{2}{*}{700,50} & \multirow{2}{*}{0,05} \\
\hline & & Hayır & 97 & 56,22 & 5453,50 & & \\
\hline & \multirow[b]{2}{*}{ Kendine Güven } & Evet & 20 & 67,05 & 1341,00 & \multirow{2}{*}{809,00} & \multirow{2}{*}{0,2} \\
\hline & & Hayır & 97 & 57,34 & 5562,00 & & \\
\hline & \multirow{2}{*}{ Duygusal Zekâ } & Evet & 20 & 63,65 & 1273,00 & \multirow{2}{*}{877,00} & \multirow{2}{*}{0,49} \\
\hline & & Hayır & 97 & 58,04 & 5630,00 & & \\
\hline & \multirow{2}{*}{ Yenilikçi OIma } & Evet & 20 & 62,35 & 1247,00 & \multirow{2}{*}{903,00} & \multirow{2}{*}{0,62} \\
\hline & & Hayır & 97 & 58,31 & 5656,00 & & \\
\hline \multirow{2}{*}{$\stackrel{0}{:}$} & \multirow{2}{*}{$\begin{array}{l}\text { Teknolojik } \\
\text { Yetenekler }\end{array}$} & Evet & 20 & 64,98 & 1299,50 & \multirow{2}{*}{850,50} & \multirow[b]{2}{*}{0,38} \\
\hline & & Hayır & 97 & 57,77 & 5603,50 & & \\
\hline
\end{tabular}


Eratlı Şirin, Y., Can B., Şeker, İ, ve Şirin, T. (2021). Futbol Antrenörlerinin Girișimcilik Eğilimleri ve Teknolojik Yeteneklerinin İncelenmesi. Gaziantep Üniversitesi Spor Bilimleri Dergisi, 6(3), 279 - 297.

Tablo 7 incelendiğinde, ÖAYGÖ'nin fırsatları görme alt boyutunda girişimcilik eğitimi olanların lehine istatistiksel olarak anlamlı fark tespit edilmiştir $(p<0,05)$. ÖAYGÖ'nin diğer hiçbir alt boyutları ve TYÖ'nde ise istatistiksel olarak fark görülmemiştir $(p>0,05)$.

Tablo 8. Katılımcıların ailelerinde girişimci olma durumlarına ilişkin Mann-Whitney U testi sonuçları

\begin{tabular}{|c|c|c|c|c|c|c|c|}
\hline & & $\begin{array}{c}\text { Ailede } \\
\text { Girişimci }\end{array}$ & $\mathbf{N}$ & S.o & S.T & $\mathbf{U}$ & $\mathbf{p}$ \\
\hline \multirow{10}{*}{$\begin{array}{l}: 0 \\
\text { : } \\
\text { : }\end{array}$} & \multirow{2}{*}{ Risk Alma } & Evet (Var) & 11 & 63,18 & 695,00 & \multirow{2}{*}{537,00} & \multirow{2}{*}{0,66} \\
\hline & & Hayır (Yok) & 106 & 58,57 & 6208,00 & & \\
\hline & \multirow{2}{*}{ Fırsatları Görme } & Evet (Var) & 11 & 60,50 & 665,50 & \multirow{2}{*}{566,50} & \multirow{2}{*}{0,87} \\
\hline & & Hayır (Yok) & 106 & 58,84 & 6237,50 & & \\
\hline & \multirow{2}{*}{ Kendine Güven } & Evet (Var) & 11 & 68,18 & 750,00 & \multirow{2}{*}{482,00} & \multirow{2}{*}{0,34} \\
\hline & & Hayır (Yok) & 106 & 58,05 & 6153,00 & & \\
\hline & \multirow[b]{2}{*}{ Duygusal Zekâ } & Evet (Var) & 11 & 59,14 & 650,50 & \multirow[b]{2}{*}{581,50} & \multirow[b]{2}{*}{0,98} \\
\hline & & Hayır (Yok) & 106 & 58,99 & 6252,50 & & \\
\hline & \multirow{2}{*}{ Yenilikçi Olma } & Evet (Var) & 11 & 67,73 & 745,00 & \multirow{2}{*}{487,00} & \multirow{2}{*}{0,36} \\
\hline & & Hayır (Yok) & 106 & 58,09 & 6158,00 & & \\
\hline \multirow{2}{*}{$\stackrel{0}{:}$} & \multirow{2}{*}{$\begin{array}{l}\text { Teknolojik } \\
\text { Yetenekler }\end{array}$} & Evet (Var) & 11 & 68,68 & 755,50 & \multirow{2}{*}{476,50} & \multirow{2}{*}{0,31} \\
\hline & & Hayır (Yok) & 106 & 58,00 & 6147,50 & & \\
\hline
\end{tabular}

Tablo 8 incelendiğinde, ailede girişimci olma değişkenine göre ÖAYGÖ'nin alt boyutları ve TYÖ'de istatistiksel olarak fark görülmemiştir $(p>0,05)$.

Tablo 9. Katılımcıların teknoloji kullanımı ile ilgili ders veya kurs alma durumlarına ilişkin Mann-Whitney U testi sonuçları

\begin{tabular}{|c|c|c|c|c|c|c|c|}
\hline & & $\begin{array}{l}\text { Teknoloji } \\
\text { Ders/Kurs }\end{array}$ & $\mathbf{N}$ & S.O & S.T & U & $\mathbf{p}$ \\
\hline \multirow{10}{*}{ 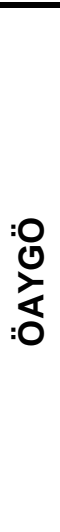 } & \multirow{2}{*}{ Risk Alma } & Evet & 65 & 63,85 & 4150,00 & \multirow{2}{*}{1375,00} & \multirow{2}{*}{0,08} \\
\hline & & Hayır & 52 & 52,94 & 2753,00 & & \\
\hline & \multirow{2}{*}{ Fırsatları Görme } & Evet & 65 & 63,88 & 4152,00 & \multirow{2}{*}{1373,00} & \multirow{2}{*}{0,08} \\
\hline & & Hayır & 52 & 52,90 & 2751,00 & & \\
\hline & \multirow{2}{*}{ Kendine Güven } & Evet & 65 & 62,68 & 4074,50 & \multirow{2}{*}{1450,50} & \multirow{2}{*}{0,18} \\
\hline & & Hayır & 52 & 54,39 & 2828,50 & & \\
\hline & \multirow{2}{*}{ Duygusal Zekâ } & Evet & 65 & 63,66 & 4138,00 & \multirow{2}{*}{1387,00} & \multirow{2}{*}{0,09} \\
\hline & & Hayır & 52 & 53,17 & 2765,00 & & \\
\hline & \multirow{2}{*}{ Yenilikçi Olma } & Evet & 65 & 70,27 & 4567,50 & \multirow{2}{*}{957,50} & \multirow{2}{*}{0,00} \\
\hline & & Hayır & 52 & 44,91 & 2335,50 & & \\
\hline \multirow{2}{*}{$: 0$} & \multirow{2}{*}{$\begin{array}{l}\text { Teknolojik } \\
\text { Yetenekler }\end{array}$} & Evet & 65 & 71,38 & 4639,50 & \multirow{2}{*}{885,50} & \multirow{2}{*}{$0,0 C$} \\
\hline & & Hayır & 52 & 43,53 & 2263,50 & & \\
\hline
\end{tabular}


Tablo 9 incelendiğinde, teknoloji kullanımı ile ilgili ders veya kurs alma değişkenine göre ÖAYGÖ'nin yenilikçi olma alt boyutu ve teknolojik yetenekler ölçeği lehine istatistiksel olarak anlamlı fark tespit edilmiştir $(p<0,05)$. ÖAYGÖ'nin diğer hiçbir alt boyutlarında istatistiksel olarak fark görülmemiştir $(p>0,05)$.

Tablo 10. Katıımcıların yaş değişkenine göre ÖAYGÖ ve TYÖ karşıllaşııması (Spearman Correlation)

\begin{tabular}{lllll}
\hline & & \multicolumn{3}{c}{ Yaş } \\
\cline { 3 - 5 } & & $\mathbf{n}$ & $\mathbf{r}$ & $\mathbf{p}$ \\
\hline \multirow{2}{*}{$:$} & Risk Alma & 117 & $-0,21^{*}$ & 0,02 \\
\cline { 2 - 5 } & Fırsatları Görme & 117 & $-0,11$ & 0,21 \\
\cline { 2 - 5 }$: 0$ & Kendine Güven & 117 & $-0,20^{*}$ & 0,02 \\
\cline { 2 - 5 } & Duygusal Zekâ & 117 & $-0,05$ & 0,59 \\
\cline { 2 - 5 } & Yenilikçi OIma & 117 & $-0,14$ & 0,12 \\
\hline \multirow{2}{*}{$:$} & Teknolojik Yetenekler & 117 & 0,09 & 0,30 \\
\hline
\end{tabular}

Tablo 10 incelendiğinde, yaş değişkeni ile ÖAYGÖ'nin risk alma $\left(r=-0,21^{*}\right)$ ve kendine güven $\left(r=-0,20^{*}\right)$ alt boyutu arasında düşük düzeyde negatif yönlü ilişki tespit edilmiştir. Yaş değişkeni ile ÖAYGÖ'nin diğer alt boyutları ve TYÖ arasında ise anlamlı bir ilişki yoktur $(p>0,05)$.

Tablo 11. ÖAYGÖ ve TYÖ'nin Alt Boyutlarının Karşılaştırması (Spearman Correlation)

\begin{tabular}{llccc}
\hline & & \multicolumn{3}{c}{ Teknolojik Yetenekler } \\
\hline & & $\mathbf{n}$ & $\mathbf{r}$ & $\mathbf{p}$ \\
\cline { 2 - 5 } & \multicolumn{1}{c}{ Risk Alma } & 117 & $0,35^{\star \star}$ & 0,00 \\
\cline { 2 - 5 } & Firsatları Görme & 117 & $0,48^{\star \star}$ & 0,00 \\
\cline { 2 - 5 }$: 0$ & Kendine Güven & 117 & 0,05 & 0,53 \\
\cline { 2 - 5 } & Duygusal Zekâ & 117 & $0,38^{\star \star}$ & 0,00 \\
\cline { 2 - 5 } & Yenilikçi Olma & 117 & $0,54^{\star \star}$ & 0,00 \\
\hline
\end{tabular}

Tablo 11 incelendiğinde, Teknolojik yetenekler ile ÖAYGÖ'nin alt boyutları arasında kendine güven hariç tüm boyutlar arasında pozitif yönlü ilişki olduğu tespit edilmiştir $(p<0,05)$.

\section{Tartışmave Sonuç}

$\mathrm{Bu}$ araştırma futbol antrenörlerinin girişimcilik eğilimleri ve teknolojik yeteneklerinin incelenmesi amacıyla yapılmıştır. Bu amaçla elde edilen bulgulara 
Eratlı Şirin, Y., Can B., Şeker, İ, ve Şirin, T. (2021). Futbol Antrenörlerinin Girişimcilik Eğilimleri ve Teknolojik Yeteneklerinin İncelenmesi. Gaziantep Üniversitesi Spor Bilimleri Dergisi, 6(3), 279 - 297.

baktığımızda, eğitim durumu, antrenörlükte çalışma yılı ve aylık gelir durumu ve teknoloji kullanımı ile ilgili ders/kurs alma değişkenlerinin antrenörlerin girişimcilik eğilimleri ve teknolojik yetenekleri üzerinde kısmen de olsa etkili olduğu söylene bilinirken. Ayrıca yaş ve teknolojik yetenekler değişkenleri ile futbol antrenörlerin girişimcilik eğilimleri arasında bir ilişki olduğu görülmektedir.

Bulgularımıza göre lise mezunu olan futbol antrenörlerinin risk alma eğilimi diğer eğitim seviyelerine göre daha yüksek bulunmuştur. Türkiye'de çok başarılı girişimcilerin çok farklı eğitim düzeylerinden gelebilmeleri bu bulgumuza örnek olarak gösterilebilinir. Ayrıca araştırma bulgularımıza göre eğitim durumu değişkeni ile teknolojik yetenekler arasında istatistiksel olarak anlamlı fark olmamasının nedeni olarak, futbol antrenörlerinin almış oldukları eğitimlerin içeriklerinde teknolojik yeteneklere yer verilmemesinden kaynaklı olduğu söylenebilir. Eğitim seviyesi bakımından girişimcilik ölçeğinin diğer hiçbir alt boyutları ve teknolojik yetenekler ölçeğinde herhangi bir farklılık görülmemiştir (Tablo 4). Girşimcilik ve teknolojik yetenekler öleçeği ile ilgili alan yazın incelendiğinde araştırma bulgularımızla paralel bir çalışmaların olduğu görülmektedir (Saraç ve Kahyaoğlu, 2011; Yüceol, 2018; Genç, 2015; Eren ve Çiçeklioğlu, 2020).

Katılımcıların gelir durumlarına göre girişimcilik ölçeğinin hiçbir alt boyutunda ve teknolojik yetenekler ölçeğinde fark bulunmamıştır (Tablo 5). Futbol anternörlerinin aylık gelirleri ile girişimcilik eğilimleri arasında fark olmamasının nedeni olarak, futbol antrenörlerinin gelirlerini girişimcilik eğitimine harcamamalarından kaynaklandığı söylenebilinir. Ayrıca futbol anternörlerinin aylık gelirleri ile teknolojik yetenekleri arasında fark olmamasının nedeni olarak, futbol antrenörlerinin teknolojik yetenekleri çok fazla kullanmadıkları ve bu nedenle teknoljik yetenekler için maddi bir kaynağa intiyaçları duymadıkları söylenebilir. Girşimcilik öleçeği ile ilgili alan yazın incelendiğinde, araştırma bulgularımızla paralellik gösteren çalışmalar olduğu görülürken (Avşar, 2007; Armut, 2018; Karademir ve ark., 2018), girişimcilik ve teknolojik yetenekler öelçeği ile ilgili araştırma bulgularımızdan farklı sonuçlarınolduğu da görülmektedir (Kayaoglu ve Kurnaz, 2019; Eren ve Çiçeklioğlu, 2020).

Araştırma bulgularında, katılımcıların antrenörlükte çalışma yılı arttıkça kendilerine güvenlerinin de arttığı görülürken, girişimcilğin diger alt boyutlarında ve teknolojik yetenekler ölçeği boyutunda herhangi bir fark görülmemiştir (Tablo 6). Bulgularımıza göre antrenörlerin mesleklerinde tercübe kazanmaları kendilerine güvenlerini arttırdıgını söyleyebiliriz. Bununla beraberfutbol antrenörlerinin çalışma 
Eratlı Şirin, Y., Can B., Şeker, İ, ve Şirin, T. (2021). Futbol Antrenörlerinin Girişimcilik Eğilimleri ve Teknolojik Yeteneklerinin İncelenmesi. Gaziantep Üniversitesi Spor Bilimleri Dergisi, 6(3), 279 - 297.

yılları ile teknolojik yetenekleri arasında bir fark olmamasını futbol antrenörlerinin çalışma metodları içinde teknolojik yeteneklerin çok fazla yer almaması söylenebilir. Girşimcilik ve teknolojik yetenekler öleçeği ile ilgili alan yazın incelendiğinde; araştırma bulgularımızla paralellik gösteren çalışmalar olduğu görülmektedir (Karademir ve ark., 2018; Şirin, 2019; Eren ve Çiçeklioğlu, 2020).

Araştırma bulgularında, katılımcıların girişimcilik eğitimi alanlarının fırsatları görme eğilimleri yüksekken girişimciliğin diğer hiçbir alt boyutunda ve teknolojik yetenekler ölçeğinde ise fark görülmemiştir.(Tablo 7). Girişimcilik dersinin bireylerin çevresindeki değişimler hakkında farkındalık oluşturması, fırsatları daha iyi değerlendirmelerine olanak sağlaması, topluma yönelik olguları çok yönlü olarak değerlendirme becerisi ve girişimciliğe dair birçok davranış kazandırmasından dolayı futbol antrenörlerinin fırsatları görmesine katkı sağladığını söyleyebiliriz. Ayrıca bulgumuza göre girişimcilik eğitimi alıp/almama durumunun futbol antrenörlerinin her ne kadar fırsatları görmesinde etkili olsada teknolojik yetenekler üzerinde etkili olmadığı görülmektedir. Bu sonucun nedeni olarak, bireylere girişimcilik eğitimi verilirken risk alma, fırsatları görme, kendine güven, duygusal zekâ ve yenilikçi olma gibi özelliklerin ön planda tutulduğu teknolojik yeteneklerin ise girişimcilik eğitimi içerisinde çok fazla yer almamasından kaynaklı olduğu söylenebilir. Girşimcilik öleçeği ile ilgili alan yazın incelendiğinde, araştırma bulgularımızla paralellik gösteren çalışmalara baktıgımızda; Karataş (2018), İbicioğlu, Taş ve Özmen'in (2010), Patır ve Karahan'ın (2010), Keat, Selvarajah ve Meyer (2011), Yüzüak (2010), Souitaris ve ark., (2007), Karimi ve ark., (2012), Fayolle ve ark., (2006), Doğan (2015) ve Bozkurt, Aslan ve Göral, (2011) üniversite öğrencileri üzerine yapmış oldukları araştırmaya göre girişimcilik dersi alan katılımcıların almayanlara göre daha yüksek girişimcilik eğilimine sahip olduğu görülmektedir. Teknolojik yetenekler ölçeği ile ilgili alan yazın incelendiğinde; konuyla ilgili yapılan araştırmaya rastlanmamıştır.

Araştırmamıza göre, katılımcıların ailede girişimci olma değişkenine göre girişimcilik ölçeğinin hiçbir alt boyutunda ve teknolojik yetenekler ölçeğinde fark görülmemiştir (Tablo 8). Bu durumu ailede girişimci olanların bu yeteneklerini yansıtamadıkları şeklinde yarumlayabiliriz. Fakat genel ortalmalara baktıgımızda tüm alt boyutlarda aile girişimci olanların olmayanlardan daha fazla girişimci eğilime sahip oldugu görülmektedir. Katılımcıların ailelerindeki girişimci olan bireylerin daha tecrübeli ve yönlendirme konusunda daha geniş bir bakış açısına sahip olduğundan ve ayrıca katılımcılara gerçekçi ve ulaşılabilir bir rol model olduklarından katılımcılarda girişimcilik ve teknolojik yetenekler düzeylerinin yükselmesine neden 
olduğu düşünülmektedir. Girşimcilik öleçeği ile ilgili alan yazın incelendiğinde; Karataş (2018), Keleş ve ark., (2012) 'in üniversite öğrencileri üzerine yapmış oldukları araştırmanın sonuçlarına göre ailelerinde girişimci olanların girişimcilik düzeylerinin daha yüksek olduğu yönündedir. Teknolojik yetenekler ölçeği ile ilgili alan yazın incelendiğinde; konuyla ilgili yapılan araştırmaya rastlanmamıştır.

Araştırmamıza göre, katılımcıların teknoloji kullanım eğitimi alma değişkenine göre girişimcilik ölçeğinin yenilikçi olma alt boyutu ve teknolojik yetenekler ölçeğinde eğitim alanların lehine anlamlı farklılık görülürken, girişimcilik ölçeğinin diğer hiçbir alt boyutunda fark görülmemiştir (Tablo 9). Bu sonuçtan hareketle teknoloji kullanım ile ilgili kendini geliştiren antrenörlerin teknoloji dersi almayanlara nazaran daha fazla yenilikçi bir yapıda oldugu yani daha fazla girişimci bir eğilimde olduklarını söyleyebiliriz. Ayrıca teknoloji kullanım ile ilgili kendini geliştiren antrenörlerin teknoloji dersi almayanlara nazaran daha fazla teknolojik yeteneklere sahip olduklarını söyleyebiliriz. Dolayısıyla teknolojik yetenekler öncelikle bireylerin kendi ilgileri doğrultusunda geliştiği daha sonra teknoloji kullanımı ile ilgili almış oldukları ders veya kursları bu ilgilerini daha çok geliştirmek ve ilerletmek amacıyla kullanıldığı söylenebilir. Girişimcilik ve teknolojik yetenekler ölçeği ile ilgili alan yazın incelendiğinde; konuyla ilgili yapılan araştırmaya rastlanmamıştır.

Araştırma bulgularımıza göre yaş arttıkça risk alma ve kendine güven düşmektedir. Bununla beraber yaş değişkeni ile girişimcilik ölçeğinin diğer hiçbir alt boyutunda ve teknolojik yetenekler ölçeğinde ise ilişki görülmemiştir (Tablo 10). Yani antrenörlerin yaşlarının ilerlemesiyle beraber birçok hususta kendilerini yetersiz görmeleri kendilerine güvenleri azaltmakta, dolaysıylada risk alma eğilimleride düşümektedir diyebiliriz. Ayrıca araştırma bulguları incelendiğinde teknolojik yeteneğin futbol antrenörlerinin yaşları üzerinde etkisinin olmamasını futbolun teknolojik yetenekten ziyade bireysel yeteneklerin ön planda tutan bir spor branşı olduğu ve antrenörlerin de bu durumu daha çok ön planda bulundurdukları söylenebilir. Girşimcilik öleçeği ile ilgili alan yazın incelendiğinde; araştırma bulgularımızla paralellik gösteren çalışmalar (Özman, 2013; Ceviz ve ark., 2016) olduğu görülürken, araştırma sonucumuzun aksi yönünde sonuçlara ulaşan çalışmalar olduğu da görülmektedir (Kılıç, Keklik ve Çalış, 2012; Şeşen ve Basım, 2012; Çermik ve Şahin, 2015; Karataş, 2018; Şeşen ve ark., 2012; Kayaoglu ve Kurnaz, 2019). Teknolojik yetenekler ölçeği ile ilgili alan yazın incelendiğinde; Eren ve Çiçeklioğlu (2020) teknolojik yetenekler, stratejik esneklik ve ürün inovasyonu 
Eratlı Şirin, Y., Can B., Şeker, İ, ve Şirin, T. (2021). Futbol Antrenörlerinin Girişimcilik Eğilimleri ve Teknolojik Yeteneklerinin İncelenmesi. Gaziantep Üniversitesi Spor Bilimleri Dergisi, 6(3), 279 - 297.

arasındaki ilişkiyi inceledikleri araştırmada yaş değişkeni ile teknolojik yetenekler fark olmadığını görülmüştür. Bu sonuç araştırma bulguları ile paralellik göstermektedir.

Araştırma bulgularında, girişimcilik ölçeğinin riks alma, fırsatları değerlendirme, duygusal zekâ ve yenilikçi olma alt boyutları ile teknolojik yetenekler ölçeği arasında orta düzeyde pozitif yönlü ilişki olduğu görülmüştür. Girişimcilik ölçeğinin kendine güven alt boyutu ile teknolojik yetenekler arasında ise herhangi bir ilişki görülmemiştir (Tablo 11). Dolayısıyla teknolojik yeteneklere sahip olma, katılımcıların riks alma, fırsatları değerlendirme, duygusal zekâ ve yenilikçi olma gibi önemli ve hayati eğilimlerini arttırdığını söylenebiliriz. Ayrıca girişimcilikte kendine güvenin teknolojik yetenekler üzerinde tek başına bir etkisi olmadığı da söylenebilir.

Bulgularımızın ortalamalarına bakılırsa sonuç olarak, eğitim durumu, antrenörlükte çalışma yılı ve aylık gelir durumu, ailede girişimci olma, girişimcilik eğitimi alma ve teknoloji kullanımı ile ilgili ders/kurs alma değişkenlerinin antrenörlerin girişimcilik eğilimleri ve teknolojik yetenekleri üzerinde kısmen de olsa etkili olduğu söylenebilir. Bununla birlikte yaş değişkenin de antrenörlerin girişimcilik eğilimleri üzerinde etkili olduğu görülmektedir. Ayrıca, girişimcilik ölçeğinin alt boyutları ve teknolojik yetenekler arasında da orta düzeyde pozitif yönlü ilişki olduğu görülmektedir.

Genç, orta ve ilerleyen yaştaki antrenörlerin girişimcilik eğilimlerinin iyi olması ve teknolojik yeteneklerinin yüksek olması amacıyla çalıştıkları spor klüplerinde belli peryotlarda uzman kişiler tarafından girişimcilik ve teknolojik yetenek gelişimi eğitimi verilebilir. Eğitimin her kademesindeki ders planlarında, antrenör gelişim kurslarında girişimcilik eğilimi ve teknolojik yeteneklerin gelişimine yönelik derslere yer verilecek şekilde düzenleme yapılabilir. Klup yöneticilerinin yeni teknolojik aletleri antrenörlerin kullanımına sunmaları ve antrenörlerin gelişimlerini arttırmaları için onları ulusal ve uluslar arası girişimcilik ve teknoloji yetenek gelişimi seminerleri ve kurslarına teşvik etmeleri önerilebilinir.

\section{Öneriler}

1. Genç, orta ve ilerleyen yaştaki antrenörlerin girişimcilik eğilimlerinin iyi olması ve teknolojik yeteneklerinin yüksek olması amacıyla çalıştıkları spor kulüplerinde belli periyotlarda uzman kişiler tarafından girişimcilik ve teknolojik yetenek gelişimi eğitimi verilebilir. 
2. Eğitimin her kademesindeki ders planlarında, antrenör gelişim kurslarında girişimcilik eğilimi ve teknolojik yeteneklerin gelişimine yönelik derslere yer verilecek şekilde düzenleme yapılabilir.

3. Kulüp yöneticilerinin yeni teknolojik aletleri antrenörlerin kullanımına sunmaları ve antrenörlerin gelişimlerini arttırmaları için onları ulusal ve uluslar arası girişimcilik ve teknoloji yetenek gelişimi seminerleri ve kurslarına teşvik etmeleri önerilebilinir.

\section{Kaynaklar}

Akyos, M. (2006). Sürekli Yenilikçilik (Innovasyon) İçin Teknolojik Yetenek Değerlendirmesi (Technology Audit). TmmobMmo Endüstri Mühendisliği Dergisi (2), 6-12.

Armut B. (2018). 4. Sınıf sosyal bilgiler öğretmenliği adaylarının girişimcilik becerisi düzeylerinin çeşitli değişkenler açısından incelenmesi. IJOFE, 4(1): 39-56.

Avşar, M. (2007). Yüksek öğretimde öğrencilerin girişimcilik eğilimlerinin araştırılması. Ankara: Çukurova Yayınları

Bozkurt, Ö., Aslan, Z. ve Göral, M. (2011). Yüksek öğretimde verilen girişimcilik eğitiminin öğrencilerin girişimcilik eğilimine etkisi: teknik program ve sosyal program karşılaştırmalı bir araştırma, İstanbul: Uluslararası Yönetim Kongresi: Yeni Yönelişler ve Sorunlar, 2.cilt, Bölüm VIII, 822-833.

Büyüköztürk, Ş., Kılıç Çakmak, E., Akgün, Ö.E., Karadeniz, Ş. \& Demirel, F. (2017). Bilimsel araştırma yöntemleri (23. Baskı). Ankara: Pegem Akademi.

Cerev, G., \& Saylan, B. (2021). Çalışanların Demografik Özelliklerinin Girişimcilik Algısına Etkisi: Sağıı Sektörü Çalışanlarına Yönelik Nicel bir Araştırma. Fırat Üniversitesi Sosyal Bilimler Dergisi, 31(1), 245-260.

Ceviz Ö.N., TEKTAŞ M., Yayla A.I.., Polat Z. (2016). Meslek yüksekokullarında öğrenim gören gençlerin girişimcilik eğilimleri üzerine bir araştırma. Eğitim ve Öğretim Araştırmaları Dergisi. 5 (37): 319-331.

Çermik F, Şahin İ. (2015). Sosyal bilgiler öğretmen adaylarının sosyal girişimcilik özelliklerinin çeşitli değişkenler açısından incelenmesi. CRE, 1(2): 76-88.

Çetinkaya Bozkurt Ö. Vd, 2012. "Türkiye'de Girişimciliğin Gelişimi: Girişimciler Üzerinde Nitel Bir Araştırma" Süleyman Demirel Üniversitesi Sosyal Bilimler Enstitüsü Dergisi Yıl: 2012/1, Sayı:15, s: 229-247

Deveci, İ.,\& Çepni, S. (2015).Öğretmen adaylarına yönelik girişimcilik ölçeğinin geliştirilmesi: Geçerlik ve güvenirlik çalışması. International Journal of Human Sciences, 12(2), 92-112. https://doi.org/10.14687/ijhs.v12i2.3240 
Doğan, E. (2015). The effect of entreprenurship education on entrepreneurial Intentions of University Students in Turkey, İstanbul Üniversitesi İktisat Fakültesi Ekonometri ve İstatistik Dergisi, Sayı:23, 79-93.

Eren, A.S., \& Çiçeklioğlu, H. (2020). Teknolojik Yetenekler, Stratejik Esneklik ve Ürün İnovasyonu Arasındaki İlişkilerin Tespiti: TR63 Bölgesindeki Mobilya İmalatçıları Üzerine Bir Araştırma, BMIJ, (2020), 8(4): 1033-1080, doi: http://dx.doi.org/10.15295/bmij.v8i4.1614

Fayolle, A., Gailly, B., \& Lassas-Clerc, N. (2006). Effect and Counter-Effect of Entreprenurship Education and Social Context on Student's Intentions, Estudios de Economia Aplicada, Vol:24, No:2, 509-523.

Genç, K. Y. (2015). Girişimcilik Kurslarına Katılanların Temel Eğilimleri Üzerine bir Araştırma. Dokuz Eylül Üniversitesi İşletme Fakültesi Dergisi, 16(2), 155-175.

Grint, K. ve Woolgar, S. (1997). Themachine at work: Technology, workandorganization (Cambridge PolityPress).

Işık Nihat. vd., 2011." İktisadi Büyümede Girişimciliğin Rolü "Girişimcilik ve Kalkınma Dergisi (6:1) 2011 Journal of Entrepreneurship and Development s. 148-178

İbicioğlu, H., Taş, S. ve Özmen H. İ. (2010). Üniversite eğitiminin girişimcilik düşüncesinin değişimine etkisi: üniversite öğrencileri üzerine bir uygulama. Alanya İşletme Fakültesi Dergisi 2(1): 53-74.

İçli, G. (2001). Eğitim, istihdam ve teknoloji. Pamukkale Üniversitesi Eğitim Fakültesi Dergisi, 9 (9), 65-71.

Karademir, E., Balbağ, M. Z., \& Çemrek, F. (2018). Öğretmen Adaylarının Girişimcilik Düzeylerinin Bazı Değişkenlere Göre İncelenmesi. Milli Eğitim Dergisi, 47(220), 177-200.

Karataş I. (2018). Beden eğitimi ve spor yüksekokulu öğrencilerinin kişilik özelliklerinin girişimcilik eğilimleri üzerindeki etkilerinin incelenmesi: Bartın Üniversitesi örneği. Yüksek Lisnas Tezi.Bartın Üniversitesi Eğitim Bilimleri Enstitüsü Beden Eğitimi ve Spor Öğretimi Ana Bilim Dalı Beden Eğitimi ve Spor Eğitimi Bilim Dalı, Bartın.

Karimi, S., Biemans, H.J.A., Lans, T., Mulder, M., \& Chizari, M. (2012). The Impact of entreprenurship education on students entreprenruail intentions and opportunity Identification perceptions. Proceeding of 26th Annual RENT Conference, Lyon, France. 
Eratlı Şirin, Y., Can B., Şeker, İ, ve Şirin, T. (2021). Futbol Antrenörlerinin Girişimcilik Eğilimleri ve Teknolojik Yeteneklerinin İncelenmesi. Gaziantep Üniversitesi Spor Bilimleri Dergisi, 6(3), 279 - 297.

Kayaoglu, A , Kurnaz, G . (2019). Üniversite Öğrencilerinin Girişimcilik Eğilimlerinin Belirlenmesi: Mardin Artuklu Üniversitesi İ̈BF Örneği . Mukaddime , 10 (2) , 643-661 . DOI: 10.19059/mukaddime.602007

Keat, O.Y., Selvarajah, C., \& Meyer, D. (2011). Inclination towards entrepreneurship among university students: An empirical study of Malaysian University students. International Journal of Business and Social Science, 2(4): 206-220.

Keleş, H.N., Özkan, T. K., Doğaner, M. ve Altunoğlu, A. E. (2012). Ön lisans öğrencilerinin girişimcilik düzeylerini belirlemeye yönelik bir araştırma. International Journal of Economicand Administrative Studies. 5(9): 108-118.

Kılıç, B., Keklik, B ve Çalış, N. (2012). Üniversite öğrencilerinin girişimcilik eğilimleri üzerine bir araştırma: Bandırma İ.İ.B.F İşletme Bölümü örneği. Süleyman Demirel Üniversitesi İktisadi ve İdari Bilimler Fakültesi Dergisi, 2(17): 423-435.

MacKenzie D. ve Wajcman, J. (1993). Introductory essay: The social sha-ping of technology. Buckingham: Open UniversityPress.

Özman, C. (2013). Spor Yöneticiliği Bölümünde Öğrenim Gören Üniversite Öğrencilerinin Girişimcilik Düzeylerinin Belirlenmesi. Yüksek Lisans Tezi, İstanbul: Marmara Üniversitesi.

Patır, S. ve Karahan, M. (2010). Girişimcilik eğitimi ve üniversite öğrencilerinin girişimcilik profillerinin belirlenmesine yönelik bir alan araştırması. İşletme ve Ekonomi Araştırmaları Dergisi, 1(2): 27-44.

Ratten, V. (2011). Sport-based entrepreneurship: Towards a new theory of entrepreneurship and sport management. International Entrepreneurship and Management Journal, 7(1), 57-69.

Saraç, M., \& Kahyaoğlu, M. B. (2011). Bireysel yatırımcıların risk alma eğilimine etki eden sosyo-ekonomik ve demografik faktörlerin analizi. BDDK Bankacılık ve Finansal Piyasalar Dergisi, 5(2), 135-157.

Souitaris, V., Zerbinati, S., \& Al-Laham, A. (2007). Do entrepreneurship programs raise entrepreneurial Intention of science and engineering students? the effect of learning, Inspiration, and resources. Journal of Business Venturing, 22: 566591.

Surujlal, J. (2004). Human Resources Management of Professional Sports Coaches. Unpublished PhD Thesis. Johannesburg: Rand Afrikaans University.

Şeşen, H. ve Basım, H. (2012). Demografik faktörler ve kişiliğin girişimcilik niyetine etkisi: spor bilimleri alanında öğrenim gören üniversite öğrencileri üzerine bir araştırma. Ege Akademik Bakış Dergisi 12(1): 21-28. 
Eratlı Şirin, Y., Can B., Şeker, İ, ve Şirin, T. (2021). Futbol Antrenörlerinin Girişimcilik Eğilimleri ve Teknolojik Yeteneklerinin İncelenmesi. Gaziantep Üniversitesi Spor Bilimleri Dergisi, 6(3), 279 - 297.

Şirin, Y. E. (2019). Coaches' Perceptions and Intentions towards Entrepreneurship. Journal of Education and Learning, 8(2), 271-278.

The benefits of using technology in sport, 23 April 2021: https://www.technogym.com/gb/wellness/the-benefits-of-using-technology-insport/

TÜSİAD (2003). "Türkiye'de Girişimcilik" Özet Bulgular 27 Şubat 2003 TS/BAS/03018

Yüceol, N. (2018). Girişimcilik eğitimi alan kişilerin girişimci kişilik özellikleri ve girişimcilik eğilimi arasındaki ilişki üzerine bir araştırma (Master's thesis, İstanbul Gelişim Üniversitesi Sosyal Bilimler Enstitüsü).

Yüzüak, E. (2010). Girişimcilik eğilimlerini etkileyen faktörler: Çanakkale Onsekiz Mart Üniversitesi Biga İ.I.B.F. örneği. Yüksek Lisans Tezi. Çanakkale Onsekiz Mart Üniversitesi Sosyal Bilimler Enstitüsü, Çanakkale.

Zhou, K. Z., \& Wu, F. (2010).Technological capability, strategic flexibility, and product innovation. Strategic Management Journal, 31(5), 547-561. Dio: https://doi.org/10.1002/smj.830 